\title{
Y-linked suppressors of the sex-ratio trait in Drosophila mediopunctata
}

\author{
ANTONIO BERNARDO DE CARVALHO* \& LOUIS BERNARD KLACZKO $\dagger$ \\ Departamento de Genética, Instituto de Biologia, Universidade Federal do Rio de Janeiro, Caixa Postal 68011, CEP \\ 21944-970, Rio de Janeiro and † Departamento de Genética e Evolução, Instituto de Biologia, Universidade Estadual de \\ Campinas, Caixa Postal 6109, CEP 13081-970, Campinas, SP, Brazil
}

\begin{abstract}
$\mathrm{X}$-linked meiotic drive causing female-biased progenies is known to occur in nine Drosophila species and is called 'sex-ratio'. In D. mediopunctata this trait is associated with the $\mathrm{X}: 21$ chromosome inversion and has variable expression. We describe here a powerful Y-linked suppressor system of sex-ratio expression in this species. There are two types of $Y$ chromosomes (suppressor and nonsuppressor) and two types of X:21 chromosomes (suppressible and unsuppressible). Sexratio expression is suppressed in males with the $21^{\text {suppressible }} / \mathbf{Y}^{\text {suppressor }}$ genotype, whereas the remaining three genotypes produce female-biased progenies.
\end{abstract}

Keywords: Drosophila mediopunctata, meiotic drive, sex-ratio, Sex ratio evolution, Y chromosome.

\section{Introduction}

Meiotic drive is the genetic condition where a heterozygote produces an unequal proportion of the two types of gametes (Sandler \& Novitsky, 1957; Lyttle, 1991). In Drosophila, meiotic drive of the $X$ chromosome against the $\mathrm{Y}$ (giving rise to female-biased progenies) is known in nine species and is called 'sexratio' (Gershenson, 1928; James \& Jaenike, 1990). In natural populations this condition is polymorphic, i.e. both driver and nondriver $\mathrm{X}$ chromosomes occur. In most cases the driver chromosomes (called hereafter 'SR') are associated with chromosomal inversions. SR chromosomes may represent a threat to a species because their fixation (as a result of the meiotic drive) will lead to its extinction due to lack of males (Gershenson, 1928; Hamilton, 1967). These polymorphisms can be stabilized by natural selection against SR, as occurs in D. pseudoobscura (Wallace, 1948; Curtsinger, 1991) and also by autosomal or Y-linked modifier genes which suppress or attenuate the meiotic drive (Stalker, 1961; Carvalho \& Klaczko, 1993).

Autosomal suppressors are expected to evolve in populations with SR chromosomes because they direct reproduction to the rarer sex, the males. This is a case of the mechanism known as Fisher's Principle, which is the most accepted evolutionary explanation for the

\footnotetext{
${ }^{*}$ Correspondence.
}

equivalence of sexual proportions (Fisher, 1930; Bull \& Charnov, 1988; Conover \& Voorhees, 1990). Autosomal suppressors of sex-ratio compatible with the operation of Fisher's Principle have been described in D. mediopunctata (Carvalho \& Klaczko, 1993); their existence has also been suggested in $D$. paramelanica (Stalker, 1961).

Any Y-linked gene that increases the transmission rate of the $\mathrm{Y}$ chromosome is expected to spread in the population (Thomson \& Feldman, 1975). This meiotic drive mechanism explains why Y-linked suppressors of sex-ratio are expected to evolve: in the presence of a $\mathrm{SR}$ chromosome, this suppressor $\mathrm{Y}$ is transmitted to half of the progeny (the males) whereas a normal $\mathrm{Y}$ is not transmitted at all (only females in the progeny). Stalker (1961) described a powerful suppressor of this kind in $D$. paramelanica; a similar one is present in $D$. affinis (Voelker, 1972) but not in natural populations of D. pseudoobscura (Policansky \& Dempsey, 1978; Beckenbach et al., 1982).

Several interesting questions are raised by the study of Y-linked suppressors of sex-ratio. First of all, they are expected to evolve in natural populations because they are strongly favoured. Second, they are not expected to be polymorphic (except transiently), as theoretical studies have shown that the conditions for stable Y polymorphisms (except neutral) are particularly restrictive, even with meiotic drive (Clark, 1987). Third, the rapid turnover of X chromosomes (driver X 
replacing nondriver $\mathrm{X}$ ) and $\mathrm{Y}$ chromosomes (suppressor ones replacing nonsuppressor ones) may explain the large role of sex chromosomes in the postzygotic isolation between closely related species (Coyne \& Orr, 1989): isolated populations can evolve different and incompatible X driver/Y suppressors systems, leading to hybrid sterility/inviability (Frank, 1991; Hurst \& Pomiankowski, 1991). As Y-linked suppressors of sexratio have been studied in detail in only one species $(D$. paramelanica), more empirical studies are clearly desirable to test current theories and to stimulate new ones.

There are four gene arrangements in the $\mathrm{X}$ chromosome of D. mediopunctata: Standard and inversions 1, 2 and 3 . Inversions 1 and 2 usually occur associated; $X$ chromosomes carrying both are named $\mathrm{X}: 2+1$ or simply $X: 21$. The $X: 2$ and $X: 21$ gene arrangements are associated with the sex-ratio trait, which has a very variable expression in D. mediopunctata (Carvalho et al., 1989; Carvalho, 1989). Previous investigations of the causes of this variability have demonstrated a male age effect (Carvalho \& Klaczko, 1992) and autosomal suppressors of sex-ratio expression (Carvalho \& Klaczko, 1993). Now we report a rather complex Y suppressor system in this species.

\section{Materials and methods}

\section{D. mediopunctata strains}

All strains are descended from flies collected at Parque Nacional do Itatiaia (State of Rio de Janeiro, Brazil) between 1986 and 1987, either from inseminated females or from males crossed with laboratory females.

ITA-24-P is a reference strain carrying the Standard ('ST') gene arrangement and free of strong autosomal suppressors. Its Y chromosome will be called hereafter Ylab.

ITC-61-A is a strain homokaryotypic for a reference $\mathrm{X}: 21$ (called hereafter $21^{\text {lab }}$ ) carrying the cytoplasm from ITA-24-P. As males with genotype $21^{\text {lab }} / Y^{\text {lab }}$ can produce sex-ratio progenies, $\mathrm{Y}^{\mathrm{lab}}$ is a nonsuppressor $\mathrm{Y}$ and $21^{\text {lab }}$ is a functional SR chromosome.

ITC-229-ET is a derivation of ITA-24-P sharing its cytoplasm, $\mathrm{X}$ chromosome and half of the autosomes.

\section{Method of detection of $Y$-linked suppressors and nonfunctional $X: 21$}

The method we have used (Fig. 1) is composed of three steps (see below; more details are given in Carvalho [1989]). Only progenies containing 20 or more flies were considered. (a) Identification of suspect wild-caught $21 / Y$ males Wild-caught $D$. mediopunctata males were crossed in the laboratory with three ITC-229-ET virgin females (ITA-24-P females were used with the ITD-332 male; see the Results). The male $\mathrm{X}$ chromosome gene arrangement was determined by the inspection of salivary gland squashes of up to eight $F_{1}$ larvae. The emerging adults were sexed and counted until vials were exhausted. The distributions of progenies of these males (and further details) are shown in Carvalho et al. (1989). Several of the $21 / Y$ males did not express the sex-ratio trait (that is, they did not produce femalebiased progenies). We selected seven of them to test their X:21 and Y chromosomes (called hereafter $21^{\text {? }}$ and $Y^{?}$ ).

(b) Synthesis and test of $21^{?} / Y^{?}$ males with controlled background We crossed in mass the $F_{1}$ of the selected male and then crossed individually $24 \mathrm{~F}_{2}$ males with three ITA-24-P virgin females to measure their sexratio expression. Half of these males were $21^{?} / Y^{?}$ (the other half were ST/Y?) and were identified by the polytene chromosomes of one daughter larva. These males carried the same $X: 21$ and $Y$ of the wild-caught parental male, the cytoplasm and half of the autosomes from ITC-229-ET. Note that the ITC-229-ET cytoplasm came from ITA-24-P. We counted the progeny of $21^{?} / \mathrm{Y}^{?}$ males and also of some ST/Y?, as a control. If at least one $\mathrm{F}_{2} 21^{?} / \mathrm{Y}^{?}$ male expressed sex-ratio (defined as a progeny containing less than 20 per cent males), we stopped at this point, concluding that in principle $21^{\text {? }}$ was functional and $Y^{\text {? }}$ was not a sex-ratio suppressor.

(c) Separation of $X: 21$ from $Y$ effects If none of the $\mathrm{F}_{2}$ $21^{?} / Y^{\prime}$ males expressed sex-ratio, we concluded that $Y^{?}$ ? was a suppressor, or $21^{\text {? }}$ was nonfunctional or that there was some specific interaction between their sex chromosomes. To discriminate among these three hypotheses we produced males with the four possible combinations between $21^{?}, 21^{\text {lab }}, Y^{?}$ and $Y^{\text {lab }}$ (Fig. 1, $F_{4}$ and $F_{6}$ generations) and measured their sex-ratio expression as before.

\section{Rationale}

This method has been designed to detect genetic variation for sex-ratio expression caused by the sex chromosomes. When a wild caught $21^{?} / Y^{?}$ male does not express sex-ratio (step a), several other factors may also be the cause: it may carry autosomal or cytoplasmic suppressors or might have been exposed in nature to some inhibitory environmental condition (temperature, food, etc.). We first separated these factors from $\mathrm{X}-\mathrm{Y}$ effects by generating several $21^{?} / \mathrm{Y}^{?}$ males in suit- 


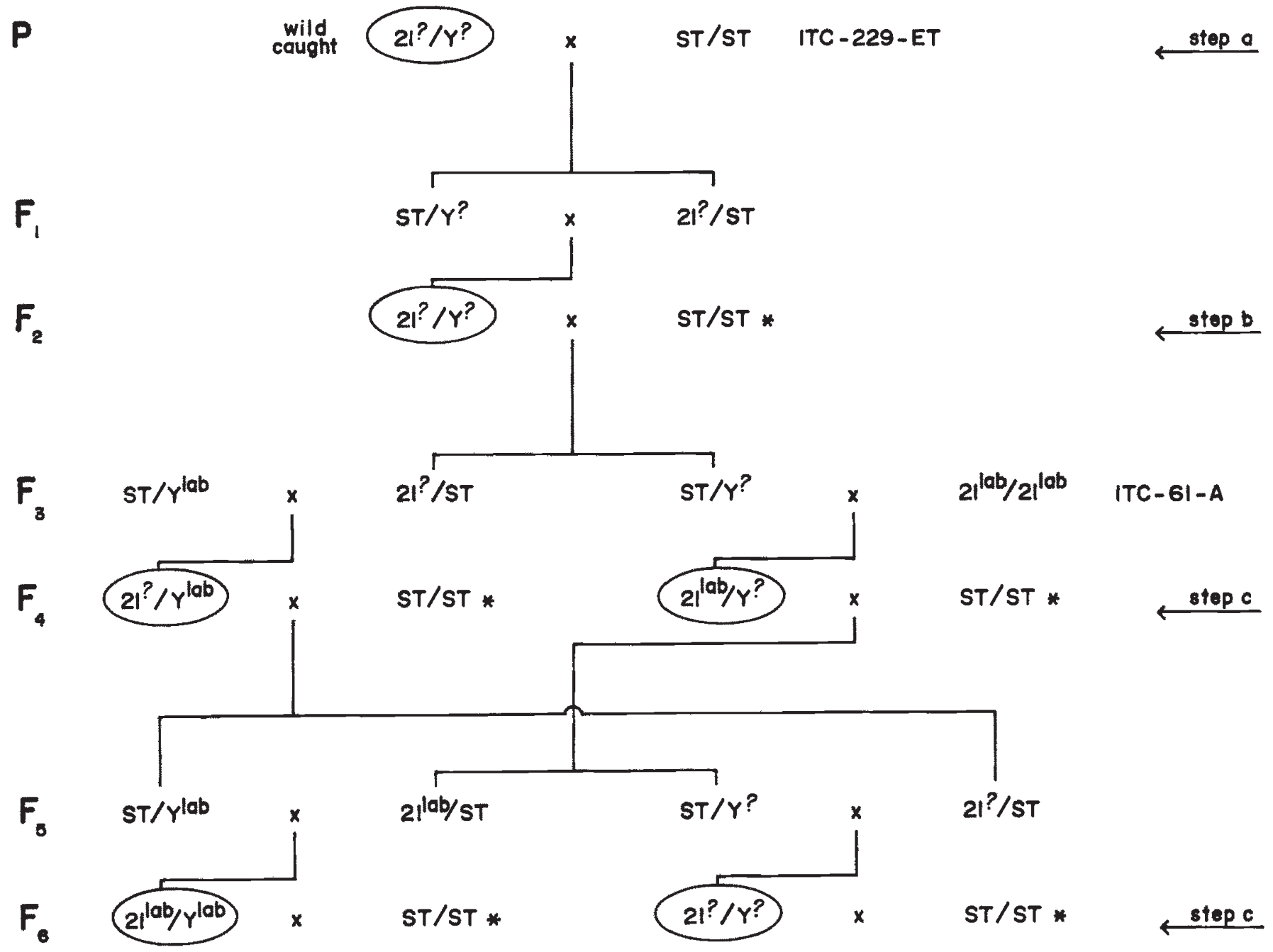

Fig. 1 Method of detection of Y-linked suppressors and nonfunctional X:21. Steps are indicated with arrows. Only the relevant genotypes are included in the scheme. Males tested for sex-ratio expression are encircled. The flies marked with an asterisk belong to the ITA-24-P strain.

able conditions for sex-ratio expression, that is, with ITA-24-P cytoplasm, autosomes segregating for ITC229-ET alleles and reared at $16.5^{\circ} \mathrm{C}$ on laboratory medium (step $b$ ). If none of them expressed sex-ratio, their sex-chromosomes were probably the cause. We tested this hypothesis and disentangled $\mathrm{X}$ from $\mathrm{Y}$ effects producing the four possible combinations between $21^{\text {? }}, 21^{\mathrm{lab}}, \mathrm{Y}^{\text {? }}$ and $\mathrm{Y}^{\mathrm{lab}}$ (step $c$ ). For example, compare the $\mathrm{F}_{6}$ males $21^{?} / \mathrm{Y}^{?}$ and $21^{\text {lab }} / \mathrm{Y}^{\text {lab }}$ (Fig. 1 ): they have exactly the same cytoplasm and autosomes so any differences between them must be caused by the $\mathrm{X}$ or $\mathrm{Y}$ chromosomes.

\section{Results}

The seven selected strains that did not express sexratio were: ITD-3.32 (31.7 per cent males in the progeny of the wild-caught male), ITE-388 (45.0 per cent), ITE-407 (28.9 per cent), ITF-355 (39.8 per cent), ITF-521 ( 64.5 per cent), ITF-446 ( 56.2 per cent) and ITF-543 (46.5 per cent). The distributions of progenies of their $F_{2} 21^{?} / Y^{?}$ males are shown in Fig. 2 .

In four strains-ITD-332, ITE-388, ITF-355 and ITF-521-the $F_{2} 21^{?} / Y^{?}$ males clearly expressed sexratio, corresponding to the situation described in step $b$ in Materials and methods. Their mean sex-ratio expression compares well with the value obtained from wildcaught $21 / \mathrm{Y}$ males (20.5 per cent; Carvalho et al., 1989). These four strains were supposed to carry a nonsuppressor $\mathrm{Y}$ and a functional $\mathrm{X}: 21$ at the beginning. The case of ITE-407 was not clear: although none of the progenies produced by its $F_{2}$ males contained less than 20 per cent males, their distribution and mean were skewed to an excess of females. 


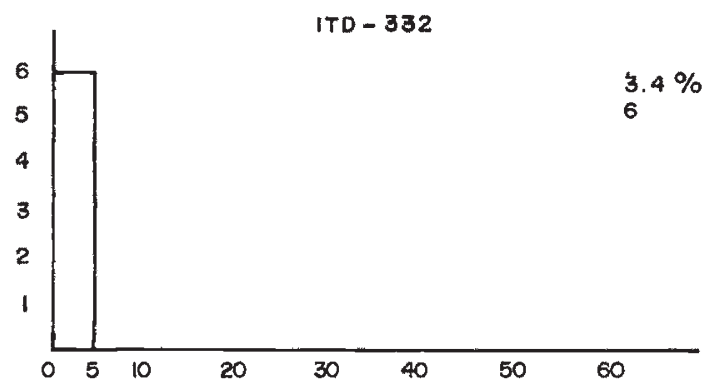

ITE - 388
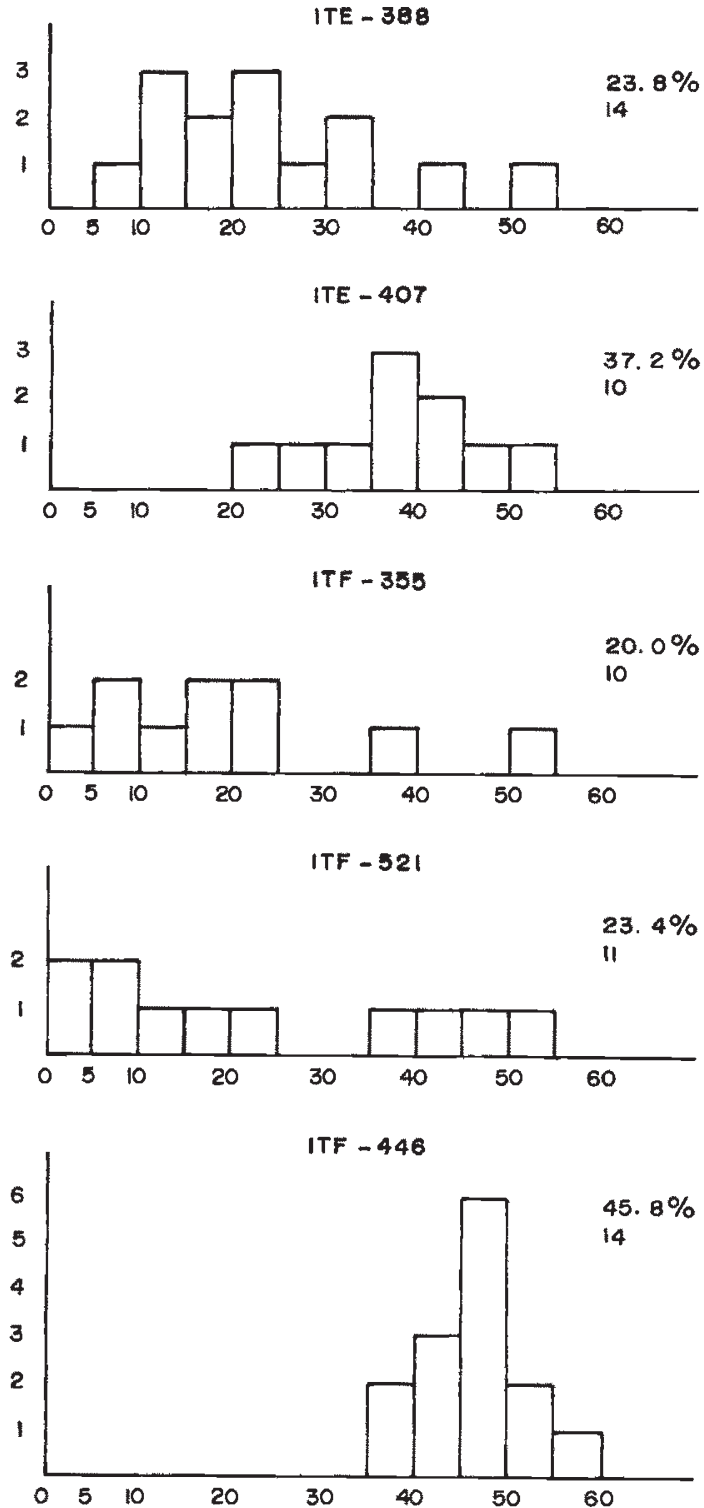

ITF -343

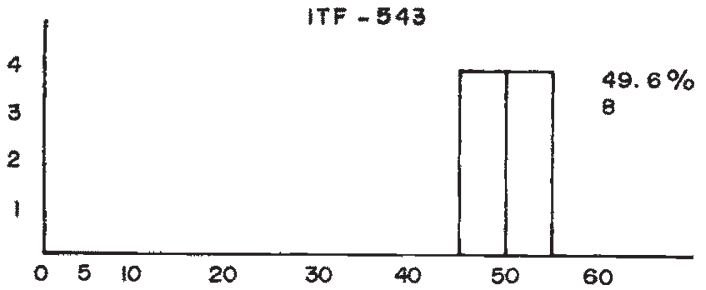

The $21^{?} / Y^{?}$ males of ITF-446 and ITF-543 were clearly non-sex-ratio, corresponding exactly to step $c$ : they must carry a suppressor $\mathrm{Y}$ or a nonfunctional $\mathrm{X}: 21$ or there was some specific interaction between their sex-chromosomes. We followed step $c$ to clarify this point. Figure 3 shows all the results produced by the application of our method to strains ITF-446 and ITF-543. $F_{4} 21^{\text {ITF-466 }} / Y^{\text {lab }}$ and $21^{\text {lab }} / Y^{\text {ITF-446 }}$ males expressed sex-ratio and the same result was obtained for the ITF-543 chromosomes. Moreover, none of the $\mathrm{F}_{6} 21^{\mathrm{ITF}-446} / \mathrm{Y}^{\mathrm{ITF}-446}$ and $21^{\mathrm{ITF}-543} / \mathrm{Y}^{\mathrm{ITF}-543}$ males were sex-ratio whereas $\mathrm{F}_{6} 21^{\text {lab }} / \mathrm{Y}^{\text {lab }}$ males (the positive control, tested only for ITF-543) again produced female-biased progenies.

To summarize, YITF-446 suppressed the sex-ratio expression of $21^{\mathrm{ITF}-446}$ but not of $21^{\text {lab }} ; 21^{\mathrm{ITF}-446}$ was suppressed by $\mathrm{Y}^{\mathrm{ITF}-446}$ but not by $\mathrm{Y}^{\mathrm{lab}}$. The same occurred with $21^{\mathrm{ITF}-543}$ and $\mathrm{Y}^{\mathrm{ITF}-543}$. The conclusion is unambiguous: there are at least two types of Y chromosomes (suppressor [Y $\left.\mathrm{Y}^{\mathrm{TTF}-446}, \mathrm{Y}^{\mathrm{ITF}-543}\right]$ and nonsuppressor $\left.\left[\mathrm{Y}^{\mathrm{lab}}\right]\right)$ and two types of $\mathrm{X}: 21$ chromosomes (suppressible $\left[21^{\mathrm{ITF}-446}, 21^{\mathrm{ITF}-543}\right]$ and unsuppressible $\left.\left[21^{\text {lab }}\right]\right) .21^{\text {suppressible }} / Y^{\text {suppressor }}$ males did not express sexratio; all other genotypes expressed it, producing female-biased progenies.

We also tested $21^{\text {ITF-446 }} / \mathrm{Y}^{\text {ITF-543 }}$ and $21^{\text {ITF-543 }} / \mathrm{Y}^{\text {ITF-446 }}$ males and found that none of them expressed sex-ratio (means: 59.7 per cent, $n=10$ and 48.3 per cent, $n=10$, respectively). Thus, the $\mathrm{X}: 21$ and $\mathrm{Y}$ chromosomes from the ITF-446 and ITF-543 strains belong to the same sex-ratio expression type.

$Y^{\text {lab }}$ appears to be consistently nonsuppressor, as ten different $X: 21$ strains can express sex-ratio with it. We also tested another unsuppressible X:21 (derived from an independent strain, ITC-221) against eight different $\mathrm{Y}$ chromosomes (three of them suppressors): none could suppress it (data not shown).

Figure 4 shows the distribution of progenies of all ST/Y, suppressed $21 / \mathrm{Y}$ and nonsuppressed $21 / \mathrm{Y}$ males tested until now. As it can be seen, in our present experimental conditions the Y-suppression is very strong, the suppressed $21 / \mathrm{Y}$ males being identical to ST/Y males in the mean sex ratios of their progenies.

The suppressed 21/Y males and their sons showed normal fertility throughout the experiment.

Fig. 2 Progenies of $F_{2} 21^{\prime} / Y^{\prime}$ males. The strain name, the mean sex ratio and the number of progenies are indicated in each histogram. Abscissae-per cent males; ordinatesabsolute frequency of progenies. 
$\begin{array}{ll}m & 0 \\ \dot{0} & \ddot{\theta} \\ 1 & 0 \\ 1 & 0 \\ L & 0 \\ 上 & 0\end{array}$
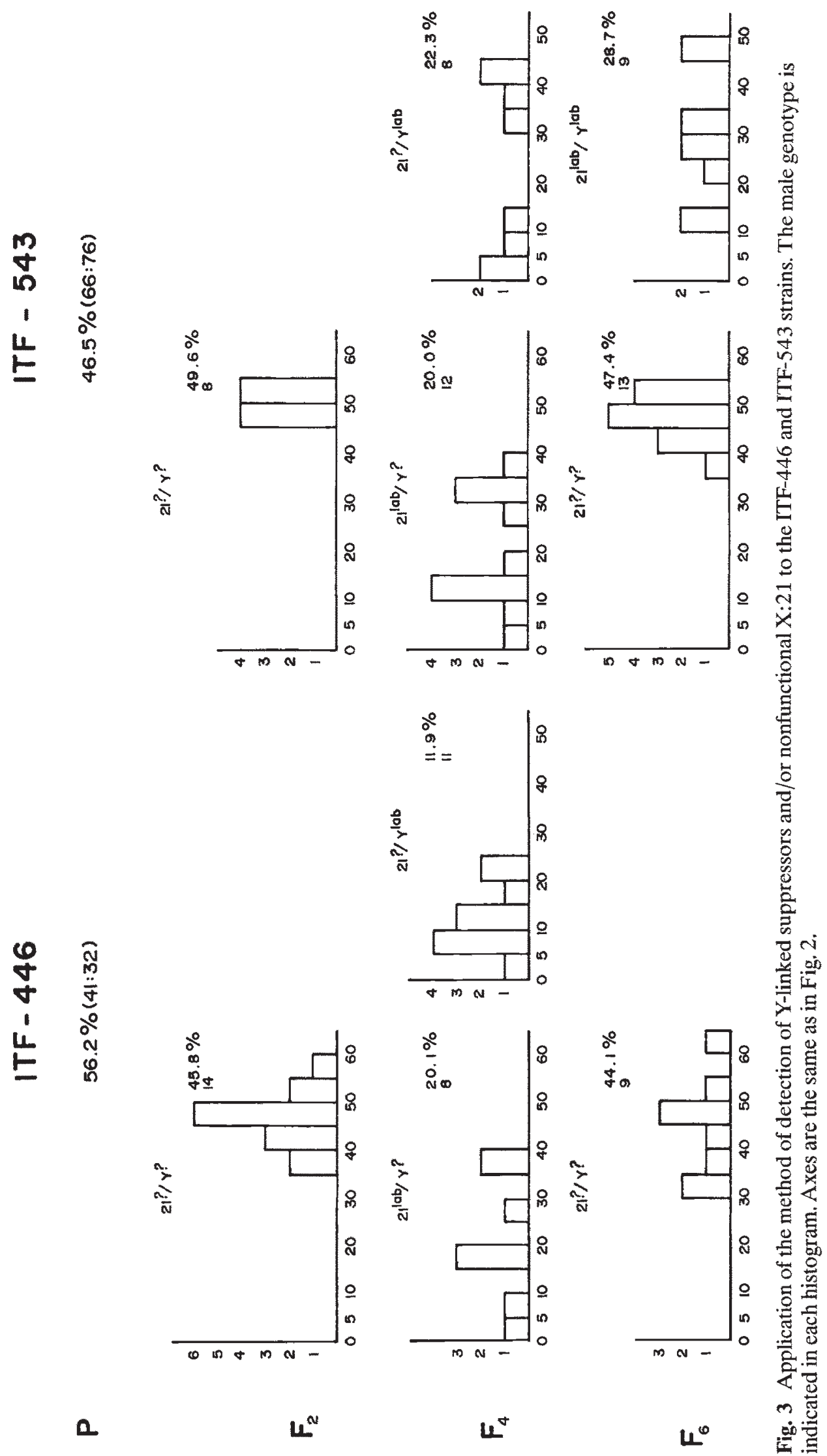

( 

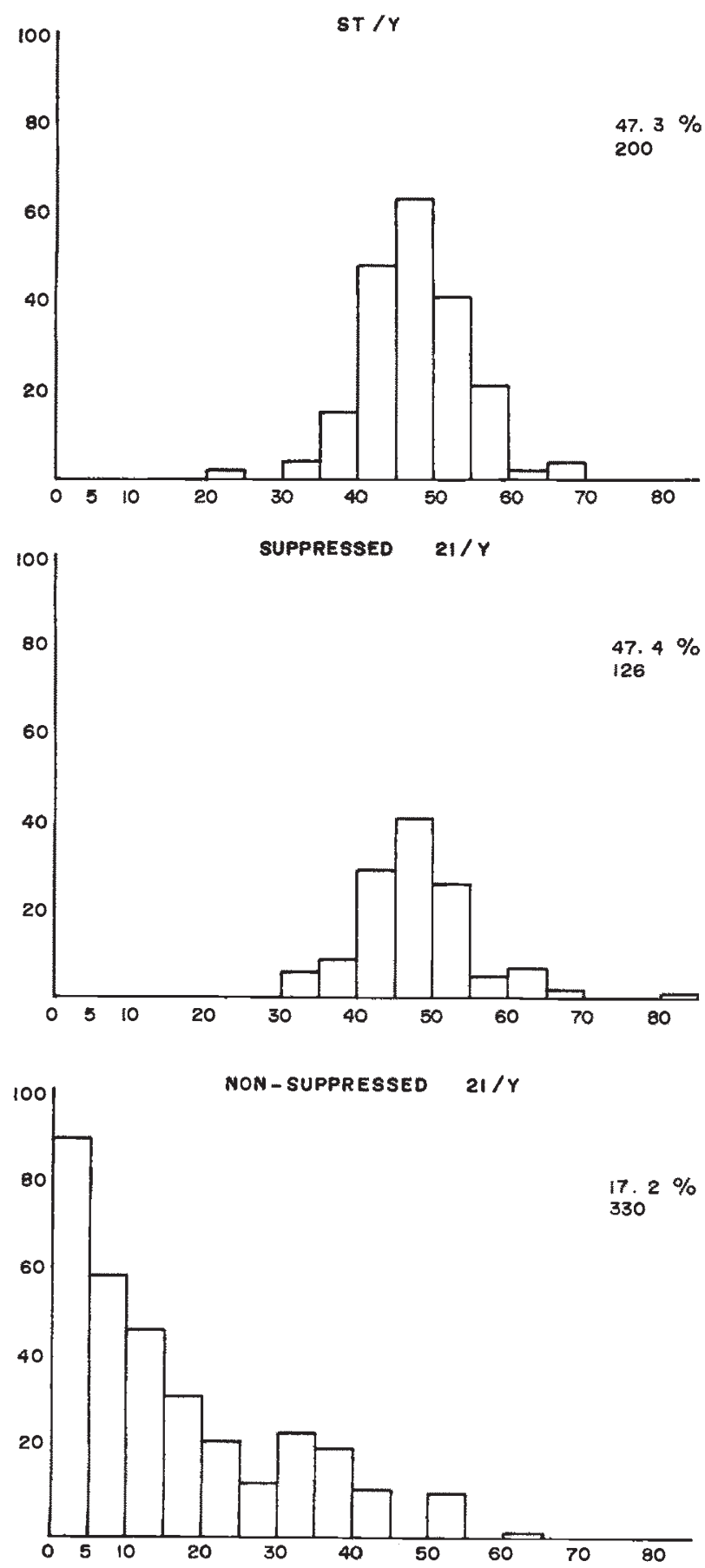

Fig. 4 Progenies of ST/Y, suppressed 21/Y and nonsuppressed $21 / \mathrm{Y}$ males. The male genotype is indicated in each histogram. Axes are the same as in Fig. 2.

\section{Discussion}

Our results demonstrate that $D$. mediopunctata has a strong Y-linked suppressor of sex-ratio expression. This suppressor system is complex, with at least two types of Y chromosomes (suppressor and nonsuppressor) and two types of $\mathrm{X}: 21$ chromosomes (suppressible and unsuppressible). Suppression results from a specific interaction between a suppressible $X: 21$ and a suppressor Y. In our experimental conditions sex-ratio expression was lost in males with this genotype; the three other genotypes ( $21^{\text {suppressible }} /$ $Y^{\text {nonsuppressor; }} \quad 21^{\text {unsuppressible }} / Y^{\text {suppressor; }} ; 21^{\text {unsuppressible }} /$ $\mathrm{Y}^{\text {nonsuppressor }}$ ) produced female-biased progenies.

The analysis of these results must take into consideration the limitations (and potentialities) of the method we have used. The main limitation of our method comes from its inability to control all the autosomal background, which could be particularly problematical given that autosomal suppressors of sex-ratio have been described in D. mediopunctata (Carvalho \& Klaczko, 1993). This meant that we could not unambiguously detect subtle variations in the sex chromosomes: the effect of a weak Y suppressor, for example, cannot be distinguished from autosomal suppressors 'diluted' by the successive backcrosses to the 'clean' laboratory background. So the existence of additional types of $\mathrm{Y}$ and $\mathrm{X}: 21$ chromosomes such as weak $\mathrm{Y}$ suppressors could not be ruled out.

Y-linked suppressors of sex-ratio expression have been studied in detail only in $D$. paramelanica which is strikingly similar to D. mediopunctata in this aspect: the two Y types (Northern and Southern) and the two SR types (Northern and Southern) of D. paramelanica also interact specifically; only males with the SR Northern/Y Southern genotype are suppressed. However, in $D$. paramelanica an intrapopulational polymorphism for SR chromosomes was not found since the two types have distinct geographical distributions (Stalker, 1961). A specific interaction between Y and SR chromosomes is also present in D. affinis (Voelker, 1972).

If meiotic drive is the sole evolutionary force acting in the sex-ratio system of $D$. mediopunctata, $\mathrm{X}: 21$ is at an advantage in relation to X:ST, in the same way as $21^{\text {unsuppressible }}$ is in relation to $21^{\text {suppressible }}$ and $Y^{\text {suppressor }}$ is in relation to $Y^{\text {nonsuppressor }}$. Because of Fisher's Principle, the autosomal suppressor alleles are also at an advantage. One would expect, thus, the fixation of at least some of the favoured alleles. However, there is an extensive polymorphism in $D$. mediopunctata for all these 'loci' (Carvalho et al., 1989; Carvalho and Klaczko, 1993; this paper). An equilibrium between meiotic drive and other fitness components could stabilize some of these polymorphisms, as has been demonstrated in D. pseudoobscura for X:ST and X:SR (Wallace, 1948; Curtsinger, 1991), but this is much more difficult with the Y polymorphism (Clark, 1987). We do not know if these polymorphisms are stable, transient or even almost neutral relics of a past history of intense oscillations in genic frequencies. 
In order to obtain some answers to these questions we are not typing $\mathrm{Y}$ and $\mathrm{X}: 21$ chromosomes from natural populations (with a reference suppressible $\mathrm{X}: 21$ and a reference suppressor $\mathrm{Y}$, respectively), controlling all the autosomal background and the age of the males (the experiments we report here were done in 1987-1988, before we knew the effect of male ageing). At present, we know that the frequency of $Y$ suppression among $21 / \mathrm{Y}$ males is approximately 10 per cent (35 per cent of the wild-caught $21 / \mathrm{Y}$ males produced suspected progenies; two males in seven suspects tested were suppressed by Y).

\section{Acknowledgements}

We thank Drs F. S. Faria, R. Ramos, A. M. Solé-Cava, B. C. Bitner-Mathé, A. Galina, A. Caciatori and two anonymous reviewers for valuable suggestions in the manuscript, and Dr Mario Impronta (NCE/UFRJ) for help with mainframe computers. We also thank Ms Mônica Bahia Schlee, Mr Ricardo Prado Schneider and NUTES/UFRJ for excellent graphical assistance and Ms Cléa Knauer da Silva for technical assistance. This work was partially supported by Conselho Nacional de Desenvolvimento Científico e Tecnológico-CNPq, Coordenação de Aperfeiçoamento do Pessoal de Ensino Superior-CAPES, Financiadora de Estudos e Projetos-FINEP, Decanato do Centro de Ciências da Saúde/UFRJ and Fundação Universitária José Bonifácio-FUJB.

\section{References}

BECKENBACH, A. T., CURTSINGER, J. W. AND POLICANSKY, D. 1982. Fruitless experiments with fruit flies: the 'sex-ratio' chromosomes of D. pseudoobscura. Drosoph. Inf. Serv., 58, 22.

BULL, J. J. AND CHARNOV, E. L. 1988. How fundamental are Fisherian sex ratios? In: Harvey, P. H. and Partridge, L. (eds) Oxford Surveys on Evolutionary Biology, vol. 5, pp. 96-135. Oxford University Press, Oxford.

CARvalHO, A. B. 1989. Sex-ratio em Drosophila mediopunctata. M. Sc. Thesis, Universidade Federal do Rio de Janeiro.

CARvalHo, A. B., PEIXoto, A. A. AND KLACZKo, L. B. 1989. Sexratio in Drosophila mediopunctata. Heredity, 62 , $425-428$.
CARvalho, A. B. AND KLACzKo, L. B. 1992. Age and sex-ratio expression in Drosophila mediopunctata. Genetica, 87 , 107-111.

CARVALHO, A. B. AND KLACZKo, L. B. 1993. Autosomal suppressors of sex-ratio in Drosophila mediopunctata. Heredity, 71, 546-551.

CLARK, A. G. 1987. Natural selection and Y-linked polymorphism. Genetics, 115, 569-577.

CONOVER, D. O. AND VOORHEES, D. A. 1990. Evolution of a balanced sex ratio by frequency-dependent selection in a fish. Science, 250, 1556-1558.

COYNE, J. A. AND ORR, H. A. 1989. Two rules of speciation. In: Otte, D. and Endler, J. (eds) Speciation and its Consequences, pp. 189-211. Sinauer Press, Sunderland, MA.

CURTSINGER, J. w. 1991. X-chromosome segregation distortion in Drosophila. Am. Nat., 137, 344-348.

FISHER, R. A. 1930. The Genetical Theory of Natural Selection. Claredon Press, Oxford.

FRANK, S. A. 1991. Divergence of meiotic drive suppression systems as an explanation for sex-biased hybrid sterility and inviability. Evolution, 45, 262-267.

GERSHENSON, s. 1928. A new sex-ratio abnormality in $D$. obscura. Genetics, 13, 488-507.

HAMILTON, w. D. 1967. Extraordinary sex ratios. Science, 156, 477-488.

HURST, L. D. AND POMIANKOwSKI, A. 1991. Causes of sex ratio bias may account for unisexuality in hybrids: a new explanation of Haldane's rule and related phenomena. Genetics, 128, 841-858.

JAMES, A. C. AND JAENIKE, J. 1990. "Sex ratio" meiotic drive in Drosophila testacea. Genetics, 126, 651-656.

LYTTLE, T. W. 1991. The genetics and evolutionary biology of meiotic drive. Am. Nat., 137, 281-282.

POLICANSKY, D. AND DEMPSEY, B. 1978. Modifiers and "sex ratio" in Drosophila pseudoobscura. Evolution, 32, 922-924.

SANDLER, L. AND NOVITSKY, E. 1957. Meiotic drive as an evolutionary force. Am. Nat., 91, 105-110.

STALKER, H. D. 1961. The genetic systems modifying meiotic drive in Drosophila paramelanica. Genetics, 46, 177-202.

THOMSOM, G. J. AND FELdMAN, M. W. 1975. Population genetics of modifiers of meiotic drive: IV. On the evolution of sexratio distortion. Theor. Pop. Biol., 8, 202-211.

VOELKER, R, A. 1972. Preliminary characterization of "sex ratio" and rediscovery and reinterpretation of "male sex ratio" in Drosophila affinis. Genetics, 71, 597-606.

wallace, B, 1948. Studies on "sex ratio" in Drosophila pseudoobscura. I. Selection and "sex ratio". Evolution, 2, 189-217. 